\title{
Simultaneous Determination of Eight Chemical Components in Angelicae Sinensis Radix and Its Herbal Products by QAMS
}

\author{
Yu Zhang $\mathbb{D},{ }^{1,2}$ Qian Li $\mathbb{D}^{1}{ }^{1}$ Yanmei Feng, ${ }^{1}$ Lan Yang, ${ }^{1}$ Qi Wang, ${ }^{1}$ Yehong Guo, \\ and Daiyu Qiu ${ }^{1}$ \\ ${ }^{1}$ Gansu Provincial Key Laboratory of Aridland Crop Science, College of Agronomy, Gansu Agricultural University, \\ Lanzhou 730070, China \\ ${ }^{2}$ Fanjia Zhuozi Health Center Huanglong County, Yanan 715700, China
}

Correspondence should be addressed to Qian Li; liqian1984@gsau.edu.cn

Received 16 January 2020; Revised 5 March 2021; Accepted 22 March 2021; Published 31 March 2021

Academic Editor: María José Trujillo-Rodríguez

Copyright (c) $2021 \mathrm{Yu}$ Zhang et al. This is an open access article distributed under the Creative Commons Attribution License, which permits unrestricted use, distribution, and reproduction in any medium, provided the original work is properly cited.

\begin{abstract}
A HPLC method has been developed for simultaneously detecting chlorogenic acid, ferulic acid, senkyunolide I, senkyunolide $\mathrm{H}$, coniferyl ferulate, senkyunolide A, ligustilide, and levistolide A in Angelicae Sinensis Radix through quantitative analysis of multicomponents by single-marker (QAMS) method with ferulic acid as internal standard substance. The relative analysis correction factors of each component in Angelicae Sinensis Radix have good reproducibility under different chromatography conditions. In addition, no significant difference of results was found between quantitative analysis of multicomponents by single-marker (QAMS) method and external standard method in determining content of these components of different Angelicae Sinensis Radix and its 12 kinds of preparations. As a result, the established QAMS method for Angelicae Sinensis Radix analysis with ferulic acid as internal standard substance is accurate and feasible, which could be used as an effective and economical method to control quality of Angelicae Sinensis Radix and its herbal products.
\end{abstract}

\section{Introduction}

Angelicae Sinensis Radix (ASR, named Danggui in Chinese) is the dried root of Angelica sinensis (Oliv.) Diels [1]. As a Chinese herbal medicine, ASR was originally described in an ancient traditional Chinese medicine classic named Shennong's Classic of Herbology, in which it is classified as top grade [2-4]. It is one of the most common traditional Chinese medicines (TCM) in our country and used in more than 80 composite formulae. ASR has the functions of tonifying blood circulation, activating blood circulation, regulating menstruation, relieving pain, moistening intestines, and defecating. It is widely applied for blood deficiency, vertigo palpitations, irregular menstruation, amenorrhea and dysmenorrhea, deficiency and cold abdominal pain, rheumatic arthralgia, intestinal dryness constipation, and other diseases [5-7]. ASR is widely distributed in Gansu, Sichuan, Hubei, Shanxi, and other provinces of China. It is not only exploited as a healthy food and drug in Asian countries but also as a nutrient in women's health and known as "female ginseng" in Europe. The preparations of ASR are mainly produced as Danggui pills, Danggui Kushen pills, Tiaojing Zhitong tablets, Fuke Tiaojing tablets, and so on [8-10].

ASR mainly contains volatile oil, organic acid, polysaccharide, brain glycosides, nucleosides, amino acids, and other types of compounds. Furthermore, over 70 compounds have been identified, including essential oils (such as ligustilide, butylphthalide and senkyunolide, and phthalide dimers), organic acids and their esters (such as ferulic acid and conifer ferulate), and vitamins and amino acids [11-14]. Among these compounds, ferulic acid has varieties of bioactivities, which has been utilized as the marker compound for quality evaluation of ASR in Chinese Pharmacopoeia. However, the characteristics of TCM determination are "multicomponents, multisites, multiefficacy, and multitargets," so it is difficult to express and evaluate the quality of TCM scientifically, effectively, and comprehensively based on a single index component [15-18]. So, the multicomponent analysis is necessary. But these methods have some 
difficulties in the practical application [19-21] such as the requirement of expensive standard substances, the difficulty to achieve the separation of the components, or the instability of the monomer, among others. The quantitative analysis of multicomponents by single-marker (QAMS) method is an analytical method for multi-index quality evaluation model suitable for the characteristics of TCM. The method used a cheap and easily available component as an internal standard substance to establish the relative calibration factors (RCF) between the internal standard substance and other components that are to be tested so that the simultaneous determination of multiple components to be tested can be realized. To some extent, this method could also reduce the analysis cost of quality control of TCM [22-24].

As known to us, the simultaneous determination of multicomponents in ASR is mainly concentrated on ferulic acid, ligustilide, and senkyunolide I through using high performance liquid chromatography (HPLC). It could not make a comprehensive and scientific evaluation of ASR and its herbal product $[25,26]$. Therefore, the QAMS was used to simultaneously determine ferulic acid, chlorogenic acid, senkyunolide I, senkyunolide $\mathrm{H}$, coniferyl ferulate, senkyunolide A, ligustilide, and levistolide A in this study, the ferulic acid was used as internal standard substance, and the RCF of other compounds was established. The established method could simultaneously determine the contents of 8 active components (Figure 1) in ASR and its 12 kinds of preparations, which provides a theoretical scientific basis for the total quality control and evaluation of ASR and its preparations.

\section{Experimental}

2.1. Instrument. Quantitative HPLC analysis was performed on a Waters (ACQUITY ARC) chromatography system equipped with Waters detector (2998PDA). The chromatographic column was Waters Symmetry C18 $(4.6 \mathrm{~mm} \times 250 \mathrm{~mm}, 5 \mu \mathrm{m}), \quad$ AL-104 electronic analytical balance (Cixi TIANDONG Weighing Instrument Factory), and KQ-500 B ultrasonic extractor (Shenzhen Dekang Technology Co., Ltd.).

2.2. Reagents and Materials. Ferulic acid ( $\geq 98 \%)$ was purchased from SAIN Chemical Technology Co., Ltd. (Shanghai, China), chlorogenic acid, ligustilide, senkyunolide A, SenkyunolideI, and levistolide A were purchased from Chengdu Pfeide Biotechnology Co., Ltd. (Chendu China) with purity $\geq 98 \%$, senkyunolide $\mathrm{H}$ and coniferyl ferulate were purchased from Sichuan Dexter Biological Co., Ltd. (Sichuan China) with purity $\geq 98 \%$; and 10 batches of ASR were bought from Yellow River Medicinal Material Market of Gansu Province (Gansu China), which was identified by associate professor Daiyu Qiu (Department of Traditional Chinese Medicine, Gansu Agricultural University). Concentrated Danggui pills, Xiaoyao pills, and BuZhong-Yi-Qi pills were obtained from Lanzhou Foci Pharmaceutical Co., Ltd. (Lanzhou China), Danggui
Futongning dropping pills, Tiaojing Zhitong tablets, Danggui Kushen pills, and Yangxue Qingnao granules were developed by Lanzhou Heshengtang Pharmaceutical Co., Ltd. (Lanzhou China), Yunnan Tengyao Pharmaceutical Co., Ltd. (Ynnan China), Shenyang Dongxin Pharmaceutical Co., Ltd. (Shenyang China), and Tianshli Pharmaceutical Group Co., Ltd. (Tianjin China). Wuji Baifeng pills, Bazhen Yimu pills, and Aifu Nuangong pills were produced from Beijing Tongrentang Co., Ltd. (Beijing China), and Fuke Tiaojing tablets and Niuhuang Shangqing tablets were produced from Jilin Wantong Pharmaceutical Co., Ltd. (Jilin China).

\subsection{Preparation of Mixed Standard Solution. Chlorogenic} acid, ferulic acid, senkyunolide I, senkyunolide $\mathrm{H}$, coniferyl ferulate, senkyunolide A, ligustilide, and levistolide A were accurately weighed $4.7 \mathrm{mg}, 11.1 \mathrm{mg}, 2.9 \mathrm{mg}, 3.7 \mathrm{mg}, 5.4 \mathrm{mg}$, $9.7 \mathrm{mg}, 22.2 \mathrm{mg}$, and $5.8 \mathrm{mg}$ and poured into a $5 \mathrm{~mL}$ volumetric flask to make the concentration to $0.94,2.22,0.58$, $0.74,1.08,1.94,4.44$, and $1.16 \mathrm{mg} / \mathrm{mL}$ of reference stock solution, respectively. Each reference stock solution was suck accurately and put into a $5 \mathrm{~mL}$ measuring flask, and then methanol was added to the scale and we shook them up; the concentration to $0.0564,0.0444,0.0116,0.0074,0.0648$, $0.0155,0.7104$, and $0.0116 \mathrm{mg} / \mathrm{mL}$ of the mixed reference solution was finally obtained.

2.4. Preparation of Test Solution. Dried plant material (over 40 mesh sieve, $2.00 \mathrm{~g}$ ) was extracted exhaustively with ethanol/water $(80 / 20, \mathrm{v} / \mathrm{v})(50 \mathrm{~mL})$ by an ultrasonic extractor (30 $\mathrm{min}, 40^{\circ} \mathrm{C}$ ); we waited for the extracted samples to cool and then weighted and ethanol/water $(80 / 20, \mathrm{v} / \mathrm{v})$ was added to make the weight of samples reach as high as the weight of samples before extracting, shook it well, and filtered through $0.22 \mu \mathrm{m}$ Millipore membranes.

2.5. Chromatographic Conditions. The mobile phase was acetonitrile (A)-1\% glacial acetic acid solution (B), gradient elution (0-18 min, $0 \%-19 \% \mathrm{~A}$; $18-60 \mathrm{~min}, 19 \%-100 \% \mathrm{~A}$ ); the flow rate was $1.0 \mathrm{~mL} / \mathrm{min}$, the column temperature was $30^{\circ} \mathrm{C}$, the detection wavelength was $280 \mathrm{~nm}$, and the sample volume was $10 \mu \mathrm{L}$. Under the conditions mentioned above, the chromatographic peaks of chlorogenic acid, ferulic acid, senkyunolide A, senkyunolide $H$, senkyunolide I, coniferyl ferulate, ligustilide, and levistolide A were separated well. The HPLC chromatogram of the mixed reference and $A n$ gelica test solution is shown in Figure 2.

\section{Results and Discussion}

\subsection{Method Validation}

3.1.1. Linear Range. $1,3,7,10,13$, and $18 \mu \mathrm{L}$ of the mixed control solutions were taken to determine the linear correlation under the abovementioned chromatographic conditions. The results suggested that 8 components presented good linear relationships in their determination ranges (Table 1). 
<smiles>O=C(/C=C/c1ccc(O)c(O)c1)O[C@@H]1C[C@](O)(C(=O)O)C[C@H](O)[C@H]1O</smiles>

(a)<smiles>CCCC=C1OC(=O)C2=C1CCC(O)C2O</smiles>

(c)<smiles>COc1cc(/C=C/COC(=O)/C=C/c2ccc(O)c(OC)c2)ccc1O</smiles>

(e)<smiles>CCC/C=C1\OC(=O)C2=C1CCC=C2</smiles>

(g)<smiles>COc1cc(/C=C/C(=O)O)ccc1O</smiles>

(b)<smiles>CCC/C=C1\OC(=O)C2=C1CC[C@@H](O)[C@H]2O</smiles>

(d)<smiles>CCCCC1OC(=O)C2=C1CCC=C2</smiles>

(f)<smiles>CCCSC=C1OC(=O)C2=C1CCC1C3C=C4OC(=O)C(=CSCCC)C4(CC3)C21</smiles>

(h)

Figure 1: Chemical structures of chlorogenic acid (a), ferulic acid (b), senkyunolide I (c), senkyunolide H (d), coniferyl ferulate (e), senkyunolide A (f), ligustilide (g), and levistolide A (h).

3.1.2. Precision. The mixed control solution under "Section 2.3 " was injected in $10 \mu \mathrm{L}$ for 6 times continuously, the peak area of each component was recorded, and the relative standard deviation (RSD) of each component was $0.38 \%$, $0.37 \%, 0.94 \%, 0.57 \%, 0.16 \%, 0.20 \%, 0.30 \%$, and $0.34 \%$ respectively, which showed that the precision of the instrument was good.

3.1.3. Stability Test. The mixed control solution (placed at room temperature) under "Section 2.3" was injected into HPLC at $0,4,8,12,24$, and $48 \mathrm{~h}$ for determination, the peak area of each component was recorded and, the RSD of the abovementioned components was $1.17 \%, 1.63 \%, 1.27 \%$, $0.71 \%, 1.16 \%, 1.44 \%, 0.52 \%$, and $0.71 \%$, respectively, indicating that the test solution was stable at room temperature within $48 \mathrm{~h}$.

3.1.4. Repeatability Test. Six test solutions were prepared in parallel. Under the same experimental conditions, the content of each component was $0.145 \%, 0.144 \%, 0.026 \%$, $0.007 \%, 0.062 \%, 0.011 \%, 1.77 \%$, and $0.035 \%$, and the RSD was $3.92 \%, 1.56 \%, 2.69 \%, 1.48 \%, 2.35 \%, 1.10 \%, 1.03 \%$, and $1.74 \%$, respectively, which showed that the method had good repeatability.

3.1.5. Recovery Test. 6 pieces of $1.00 \mathrm{~g}$ of known content of ASR were accurately weighted, and appropriate amount of each reference stock solution was added according to the 


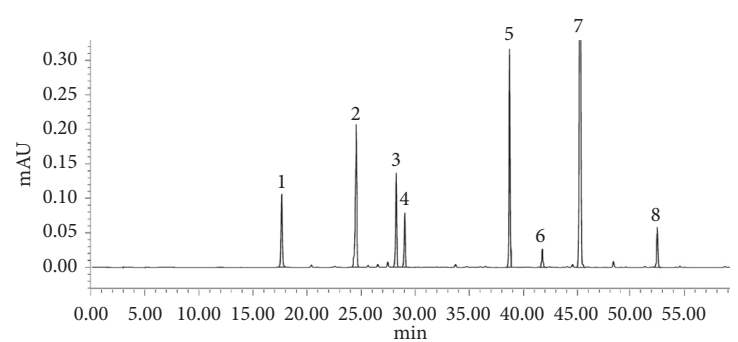

(a)

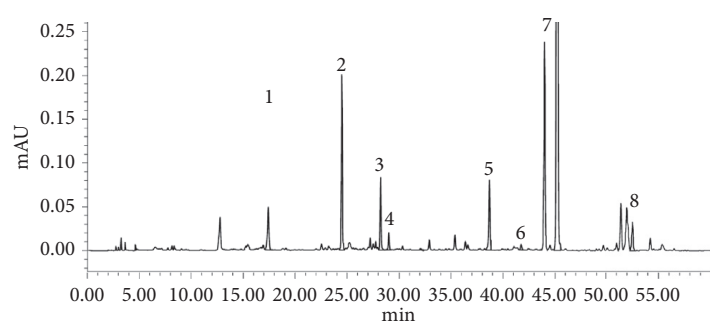

(b)

Figure 2: HPLC chromatogram of mixed standard solution (a) and Angelica test solution (b). Note. 1, chlorogenic acid. 2, ferulic acid. 3, senkyunolide I. 4, senkyunolide H. 5, coniferyl ferulate. 6, senkyunolide A. 7, ligustilide. 8, levistolide A.

TABLE 1: Investigation results of linear relationship of 8 components.

\begin{tabular}{|c|c|c|c|c|c|}
\hline Component & Linear equation & $R 2$ & Linear range $(\mu \mathrm{g})$ & LOD $(\mu \mathrm{g} / \mathrm{mL})$ & LOQ $(\mu \mathrm{g} / \mathrm{mL})$ \\
\hline Chlorogenic acid & $y=53345 x-3885$ & 0.998 & $0.056-1.015$ & 1.008 & 3.055 \\
\hline Ferulic acid & $y=11019 x+3127$ & 0.999 & $0.044-0.799$ & 3.851 & 11.670 \\
\hline Senkyunolide I & $y=58650 x+849.7$ & 0.999 & $0.012-0.209$ & 0.212 & 0.642 \\
\hline Senkyunolide $\mathrm{H}$ & $y=32679 x-1021$ & 0.999 & $0.007-0.133$ & 0.215 & 0.651 \\
\hline Coniferyl ferulate & $y=12625 x+9836$ & 0.999 & $0.065-1.166$ & 3.108 & 9.417 \\
\hline Senkyunolide A & $y=13110 x-2026$ & 0.999 & $0.016-0.280$ & 0.718 & 2.175 \\
\hline Ligustilide & $y=47561 x+8975$ & 0.999 & $0.710-12.787$ & 3.909 & 11.845 \\
\hline Levistolide A & $y=27461 x+5987$ & 0.999 & $0.012-0.209$ & 0.234 & 0.709 \\
\hline
\end{tabular}

preparation method of tested solution under "Section 2.4". The average recovery of the abovementioned eight components was calculated as $100.32 \%, 100.53 \%$, $97.78 \%$, $101.74 \%, 99.69 \%, 98.86 \%, 99.16 \%$, and $103.53 \%$, and the RSD was $3.61 \%, 2.97 \%, 2.20 \%, 2.34 \%, 2.98 \%, 3.19 \%, 3.54 \%$, and $2.54 \%$, respectively. The results illustrated that the proposed method was of good accuracy.

\subsection{Establishment of QAMS Method}

3.2.1. Calculation of Relative Correction Factors (RCF). The formula for calculating the relative correction factor is $(f)=(\mathrm{As} / \mathrm{Cs}) /(\mathrm{AR} / \mathrm{CR})$. As is the peak area of the internal standard substance, AR is the peak area of the reference substance, $\mathrm{Cs}$ is the concentration of the internal standard substance, and CR is the concentration of the reference substance. The mixed reference solution prepared in Section 2.3 was injected into HPLC for analysis according to the chromatographic conditions under Section 2.5, respectively. Besides, the chromatographic peak areas of each component were recorded. The RCF of chlorogenic acid, senkyunolide I, senkyunolide $H$, coniferyl ferulate, senkyunolide $A$, ligustilide, and levistolide A was calculated with ferulic acid as internal standard. The results are shown in Table 2. The effect of three different chromatographic columns, different column temperatures, and different volumetric flows on RCF is shown in Supplementary Materials (Tables S1-S3). The RSD of each component was less than $3.00 \%$, indicating that different chromatographic columns, different column temperatures, and different flow rates had no significant impact on the correction factors of each component, and the reproducibility was good.

3.2.2. Location of Chromatographic Peak. According to the retention time obtained in "Section 3.2.1," the relative retention value of the components and the internal reference $\left(r_{i / s}=t_{R i} / t_{s}\right)$, where $t_{R i}$ and $t_{R s}$ are the retention time of the components to be tested and the internal standard ferulic acid, respectively) and their RSDs were calculated. The results showed that the RSD of the relative retention value of each component was less than $3 \%$, indicating that the relative retention value was stable and can be used for the location of the chromatographic peak of the components to be tested. The results are shown in Table 3.

3.3. Sample Content Determination. The calculation formula of QAMS is as follows: $(\mathrm{CX})=f \times A_{X} /\left(A_{S}^{\prime} / C_{S}{ }^{\prime}\right)$. AX is the peak area of the test article, $C_{X}$ is the concentration of the test article, $A_{S}$ ' is the peak area of the internal standard substance (ferulic acid), $C_{S}$ ' is the concentration of the internal standard substance (ferulic acid), and $f$ is the RCF. The contents of each component in 6 batches of ASR and 4 kinds of its proprietary Chinese medicine were calculated by QAMS and external standard method (ESM), respectively. Each sample was determined three times. The results are shown in Table 4. It was found that the percentage difference (PD) $\mathrm{PD}=(\mathrm{QAMS}-\mathrm{ESM}) /[(\mathrm{QAMS}+\mathrm{EMS}) / 2] \times 100 \%)$ of these two methods was less than $\pm 5.0 \%$. The results of two determination methods had no significant differences, which 
TABLE 2: Results of RCF of 7 components in ASR.

\begin{tabular}{|c|c|c|c|c|c|c|c|}
\hline Injection volume $(\mu \mathrm{L})$ & $f_{\text {chlorogenic acid }}$ & $f_{\text {senkyunolide I }}$ & $f_{\text {Senkyunolide } \mathrm{H}}$ & $f_{\text {coniferyl ferulate }}$ & $f_{\text {senkyunolide A }}$ & $f_{\text {ligustilide }}$ & $f_{\text {levistolide A }}$ \\
\hline 1 & 2.701 & 0.496 & 0.582 & 1.232 & 1.837 & 1.369 & 1.148 \\
\hline 3 & 2.619 & 0.512 & 0.597 & 1.272 & 1.898 & 1.410 & 1.213 \\
\hline 7 & 2.794 & 0.481 & 0.556 & 1.250 & 1.841 & 1.333 & 1.207 \\
\hline 10 & 2.662 & 0.497 & 0.574 & 1.282 & 1.768 & 1.300 & 1.141 \\
\hline 13 & 2.653 & 0.494 & 0.564 & 1.274 & 1.777 & 1.335 & 1.132 \\
\hline 18 & 2.645 & 0.49 & 0.563 & 1.266 & 1.884 & 1.333 & 1.136 \\
\hline Mean & 2.679 & 0.495 & 0.573 & 1.263 & 1.834 & 1.347 & 1.163 \\
\hline RSD\% & 2.323 & 2.052 & 2.622 & 1.461 & 2.912 & 2.817 & 3.180 \\
\hline
\end{tabular}

TABLe 3: Relative retention values (ri/s) of 7 components to be tested and ferulic acid determined by different chromatographic columns.

\begin{tabular}{lccccccc}
\hline Chromatographic column & $r_{\text {chlorogenic acid }}$ & $r_{\text {senkyunolide I }}$ & $r_{\text {senkyunolide H }}$ & $r_{\text {coniferyl ferulate }}$ & $r_{\text {senkyunolide A }}$ & $r_{\text {ligustilide }}$ & $r_{\text {levistolide A }}$ \\
\hline Waters Symmety C 18 & 0.691 & 1.160 & 1.194 & 1.595 & 1.719 & 1.865 \\
Agilent ZORBAX SB-C & 0.669 & 1.149 & 1.184 & 1.606 & 1.719 & 1.864 & 2.169 \\
Hanbon KU60826 C & 18 & 0.666 & 1.131 & 1.162 & 1.563 & 1.703 & 1.851 \\
Mean & 0.675 & 1.147 & 1.180 & 1.588 & 1.714 & 1.860 & 2.147 \\
RSD (\%) & 2.073 & 1.286 & 1.368 & 1.408 & 0.526 & 0.429 & 0.991 \\
\hline
\end{tabular}

TABLE 4: Content of 8 components in 10 batches of ASR and its 12 kinds of preparations determined by QAMS and ESM (mg/g).

\begin{tabular}{|c|c|c|c|c|c|c|c|c|}
\hline Sample/PD & $\begin{array}{l}\text { Chlorogenic } \\
\text { acid }\end{array}$ & Ferulic acid & $\begin{array}{l}\text { Senkyunolide } \\
\text { I }\end{array}$ & $\begin{array}{c}\text { Senkyunolide } \\
\text { H }\end{array}$ & $\begin{array}{l}\text { Coniferyl } \\
\text { ferulate }\end{array}$ & $\begin{array}{c}\text { Senkyunolide } \\
\text { A }\end{array}$ & ligu & it \\
\hline & ESM QAMS & $S M$ & ESM QAMS & ESM QAMS & ESM QAMS & ESM QAMS & ESM & ESM QAMS \\
\hline 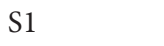 & $153 \quad 1$. & & 2620.2 & 073 & 18 & 108 & $\begin{array}{ll}703 & 17\end{array}$ & 337 \\
\hline $\mathrm{PD}$ & 3.980 & & -2.317 & -1.379 & 1.923 & -1.869 & -1.0277 & 2.924 \\
\hline S2 & $0.273 \quad 0.284$ & & $.029 \quad 1.006$ & 0.265 & 1.34 & $.107 \quad 0.104$ & 7.898 & $.538 \quad 0.555$ \\
\hline $\mathrm{PD}$ & 3.950 & & -2.260 & -1.869 & 1.807 & -2.845 & -1.031 & 3.111 \\
\hline S3 & $0.339 \quad 0.3$ & & $\begin{array}{ll}674 & 0.659\end{array}$ & 0.158 & $429 \quad 2.473$ & 0.174 & $3.201 \quad 13.065$ & $355 \quad 0.366$ \\
\hline $\mathrm{PD}$ & 4.046 & & -2.251 & -1.881 & 1.795 & -2.273 & -1.036 & 3.051 \\
\hline S4 & $.387 \quad 0.4$ & & $937 \quad 0.916$ & $.247 \quad 0.242$ & $.110 \quad 1.130$ & .2120 .208 & 7.194 & $.452 \quad 0.465$ \\
\hline $\mathrm{PD}$ & 3.802 & & -2.267 & -2.045 & 1.786 & -1.905 & -1.034 & 2.835 \\
\hline S5 & $0.387 \quad 0.4$ & & $302 \quad 0.296$ & 0.086 & 079 & $.242 \quad 0.237$ & $26.496 \quad 26.224$ & 1.071 \\
\hline $\mathrm{PD}$ & 3.802 & & -2.007 & -2.299 & 1.798 & -2.087 & -1.032 & 3.033 \\
\hline S6 & $1.94 \quad 2.019$ & & $152 \quad 0.149$ & $0.041 \quad 0.04$ & $\begin{array}{ll}.597 & 1.626\end{array}$ & $.136 \quad 0.134$ & $17.816 \quad 17.633$ & $.414 \quad 0.426$ \\
\hline PD & 3.991 & & -1.993 & -2.469 & 1.800 & -1.481 & -1.032 & 2.857 \\
\hline S7 & $0.619 \quad 0.6$ & & $359 \quad 0.3$ & $112 \quad 0.11$ & $857 \quad 0.872$ & $127 \quad 0.124$ & $2.469 \quad 12.341$ & 0.45 \\
\hline PD & 3.959 & & -2.253 & -1.802 & 1.735 & -2.390 & -1.032 & 2.931 \\
\hline S8 & $0.464 \quad 0.4$ & & $542 \quad 0.53$ & $.214 \quad 0.2$ & $.959 \quad 0.976$ & $.131 \quad 0.128$ & 9.076 & $0.438 \quad 0.451$ \\
\hline & 4.013 & & -2.239 & -1.887 & 1.757 & -2.317 & -1.030 & 2.925 \\
\hline S9 & $0.816 \quad 0.849$ & & $625 \quad 0.611$ & $094 \quad 0.092$ & $.236 \quad 1.258$ & $159 \quad 0.156$ & $10.584 \quad 10.475$ & $.335 \quad 0.345$ \\
\hline $\mathrm{PD}$ & 3.964 & & -2.265 & -2.151 & 1.764 & -1.905 & -1.035 & 2.941 \\
\hline S10 & $422 \quad 0$. & & $791 \quad 0.7$ & $174 \quad 0.1$ & $48 \quad 1.3$ & $94 \quad 0.189$ & $811 \quad 9.711$ & $102 \quad 0.414$ \\
\hline & 4.176 & & -2.302 & -1.73 & 1.838 & -2.61 & & 2.941 \\
\hline S & .6150 .6 & 6 & $433 \quad 0.423$ & $115 \quad 0.113$ & $063 \quad 0.064$ & $.094 \quad 0.092$ & 6.731 & $0.406 \quad 0.418$ \\
\hline $\mathrm{PD}$ & 3.984 & & -2.336 & -1.754 & 1.575 & -2.151 & -1.030 & 2.913 \\
\hline S12 & $052 \quad 0.0$ & & $173 \quad 0.1$ & $56 \quad 0.0$ & $\begin{array}{ll}47 & 0.0\end{array}$ & $48 \quad 0.0$ & $952 \quad 1.932$ & $101 \quad 0.105$ \\
\hline & 3.773 & & -2.339 & -1.802 & 2.105 & -2.105 & -1.030 & 3.883 \\
\hline S1 & $159 \quad 0.165$ & & $211 \quad 0.206$ & $061 \quad 0.059$ & $.060 \quad 0.061$ & $306 \quad 0.299$ & $0.737 \quad 0.730$ & $0.069 \quad 0.071$ \\
\hline $\mathrm{PD}$ & 3.704 & & -2.398 & -3.333 & 1.653 & -2.314 & -0.954 & 2.857 \\
\hline S14 & I & & $45 \quad 0.14$ & $025 \quad 0.02$ & $\begin{array}{ll}90 & 0.0\end{array}$ & $32 \quad 0.0$ & $1.040 \quad 1.030$ & $0.083 \quad 0.085$ \\
\hline $\mathrm{PD}($ & 1 & & -2.091 & -4.082 & 2.198 & -3.175 & -0.966 & 2.381 \\
\hline S15 & $0.327 \quad 0.34$ & 87 & 0.09 & $\begin{array}{ll}03 & 0.02\end{array}$ & $047 \quad 0.0$ & $.037 \quad 0.03$ & $1.348 \quad 1.334$ & $0.061 \quad 0.063$ \\
\hline $\mathrm{PD}($ & 4.192 & & -2.020 & -3.390 & 2.105 & -2.740 & -1.044 & 3.226 \\
\hline S16 & $0.048 \quad 0.050$ & & $071 \quad 0.069$ & .0220 .021 & $.022 \quad 0.023$ & $0.047 \quad 0.046$ & $0.259 \quad 0.256$ & $0.039 \quad 0.040$ \\
\hline $\mathrm{PD}$ & 4.082 & & -2.857 & -4.651 & 4.444 & -2.151 & -1.165 & 2.532 \\
\hline S17 & $0.04 \quad 0.0$ & 0.414 & $131 \quad 0.12$ & $039 \quad 0.03$ & $038 \quad 0.0$ & $162 \quad 0.15$ & $0.714 \quad 0.707$ & $0.048 \quad 0.050$ \\
\hline PD (\%) & 4.878 & & -2.3167 & -2.597 & 2.597 & -2.500 & -0.985 & 4.082 \\
\hline
\end{tabular}


TABLE 4: Continued.

\begin{tabular}{|c|c|c|c|c|c|c|c|c|c|c|c|c|c|c|}
\hline \multirow[t]{2}{*}{ Sample/PD } & \multicolumn{2}{|c|}{$\begin{array}{l}\text { Chlorogenic } \\
\text { acid }\end{array}$} & \multirow{2}{*}{$\begin{array}{c}\text { Ferulic acid } \\
\text { ESM }\end{array}$} & \multicolumn{2}{|c|}{$\begin{array}{l}\text { Senkyunolide } \\
\text { I }\end{array}$} & \multicolumn{2}{|c|}{$\begin{array}{c}\text { Senkyunolide } \\
\mathrm{H}\end{array}$} & \multicolumn{2}{|c|}{$\begin{array}{l}\text { Coniferyl } \\
\text { ferulate }\end{array}$} & \multicolumn{2}{|c|}{$\begin{array}{c}\text { Senkyunolide } \\
\text { A }\end{array}$} & \multicolumn{2}{|c|}{ ligustilide } & Levistolide A \\
\hline & ESM & QAMS & & ESM & QAMS & ESM & QAMS & ESM & QAMS & ESM & QAMS & SM & & ESM QAMS \\
\hline & 45 & & 0586 & 0.156 & & 0.068 & & & & .081 & & 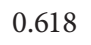 & & 058 \\
\hline & \multicolumn{2}{|c|}{4.135} & & \multicolumn{2}{|c|}{-2.597} & \multicolumn{2}{|c|}{-1.481} & \multicolumn{2}{|c|}{1.802} & \multicolumn{2}{|c|}{-2.500} & \multicolumn{2}{|c|}{-0.976} & 3.390 \\
\hline & 94 & 0.4 & & 67 & 0.16 & 051 & 0.05 & & 0.0 & 92 & 0.38 & 728 & 0.720 & $072 \quad 0.074$ \\
\hline 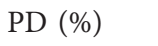 & \multicolumn{2}{|c|}{3.980} & & \multicolumn{2}{|c|}{-2.424} & \multicolumn{2}{|c|}{-1.980} & \multicolumn{2}{|c|}{1.681} & \multicolumn{2}{|c|}{-2.062} & \multicolumn{2}{|c|}{-1.105} & 2.740 \\
\hline & 75 & 1.4 & & 299 & 0.29 & 47 & 0.34 & & 1.7 & 05 & 0.98 & $-\pi$ & 1.4 & $\begin{array}{ll}36 & 0.037\end{array}$ \\
\hline & \multicolumn{2}{|c|}{3.991} & & \multicolumn{2}{|c|}{-2.369} & \multicolumn{2}{|c|}{-1.744} & \multicolumn{2}{|c|}{1.757} & \multicolumn{2}{|c|}{-2.213} & \multicolumn{2}{|c|}{-1.035} & 2.740 \\
\hline & 175 & 0.49 & 26 & 331 & 0.323 & 0.177 & 0.173 & 292 & 0.2 & 0.586 & 0.573 & 1.648 & 1.632 & $0.127 \quad 0.131$ \\
\hline & \multicolumn{2}{|c|}{3.922} & & \multicolumn{2}{|c|}{-2.446} & \multicolumn{2}{|c|}{-2.286} & \multicolumn{2}{|c|}{1.698} & \multicolumn{2}{|c|}{-2.243} & \multicolumn{2}{|c|}{-0.976} & 3.101 \\
\hline & 463 & 0.48 & 0.011 & 267 & 0.261 & 0.087 & 0.086 & 0 & 0.432 & 0.260 & 0.255 & 2.069 & 2.048 & $0.120 \quad 0.123$ \\
\hline$D(\%)$ & & & & & & & 156 & & & & & & .020 & 2.469 \\
\hline
\end{tabular}

Note. S1-S10 are 10 batches of ASR; S1 1 is concentrated Danggui pills; S12 is Danggui Kushen pills; S13 is Tiaojing Zhitong tablets; S14 is Danggui Futongning dropping pills; S15 is Xiaoyao pills; S16 is Wuji Baifeng pills; S17 is Bazhen Yimu pills; S18 is Bu-Zhong-Yi-Qi pills; S19 is Aifu Nuangong pills; S20 is Niuhuang Shangqing tablets; S21 is Yangxue Qingnao granules; and S22 is Fuke Tiaojing tablets.

illustrated that the established method was accurate and reliable.

3.4. T-Test of the Content Determination Results. Paired sample $t$-test was carried out on 7 contents of 22 samples measured by QAMS method and ESM by using SPSS22.0 software. The results showed that $P>0.05$; There was no significant difference between the two methods.

\section{Conclusion}

In this study, a QAMS method was established to determinate the contents of chlorogenic acid, senkyunolide I, senkyunolide $\mathrm{H}$, coniferyl ferulate, senkyunolide A, ligustilide, and levistolide A with the ferulic acid as the internal standard substance. The results showed that there was no significant difference between QAMS and ESM by investigating different chromatographic columns, different column temperatures, and different flow rates; the results showed that the RSDs were all less than $3.00 \%$, indicating that the change of chromatographic conditions had no significant effect on the relative correction factors of each component, and the reproduction was good. The abovementioned results indicate that the QAMS method that established could be accurately, economically, simply, and rapidly applied to the multicomponents analysis of ASR and its 12 kinds of preparations without reference substance. This work provided a scientific basis for quality control of ASR.

\section{Data Availability}

The data used to support the findings of this study are available from the corresponding authors upon request.

\section{Conflicts of Interest}

The authors have no conflicts of interest to declare.

\section{Acknowledgments}

This work was supported by the National Natural Science Foundation of China (31860102), Research Program sponsored by Gansu Provincial Key Laboratory of Aridland Crop Science, Gansu Agricultural University (No. GSCS2018-3), Discipline Construction Fund Project of Gansu Agricultural University (GSAU-XKJS-2018-086), and FuXi Young Talents Introduction Projects of Gansu Agricultural University (GSAU-RCZX201704).

\section{Supplementary Materials}

Supplementary Materials are about "repeatability of the correction factor". Table S1: effect of three different chromatographic columns on RCF of 7 components. Table S2: effect of different column temperatures on RCF of each component. Table S3: effect of different flow rates on RCF of each component. Figure S1: HPLC chromatogram of mixed standard solution (a) and Angelica test solution (b). Note: 1, chlorogenic acid; 2 , ferulic acid; 3 , senkyunolide I; 4, senkyunolide $H$; 5 , coniferyl ferulate; 6 , senkyunolide A; 7, ligustilide; 8 , levistolide A; Figures $\mathrm{C}$ and $\mathrm{D}$ are the calibration diagrams of Figures A and B, respectively. . (Supplementary Materials)

\section{References}

[1] Chinese Pharmacopoeia Commission, Pharmacopoeia of People's Republic of China, pp. 133-134, China Medical Science and Technology Press, Beijing, China, 2015.

[2] X. Li, X. Wu, and L. Huang, "Correlation between antioxidant activities and phenolic contents of radix Angelicae sinensis (Danggui)," Molecules, vol. 14, no. 12, pp. 5349-5361, 2009.

[3] L. Yi, Y. Liang, H. Wu, and D. Yuan, "The analysis of radix Angelicae sinensis (danggui)," Journal of Chromatography A, vol. 1216, no. 11, pp. 1991-2001, 2009.

[4] W. H. Huang and C. Q. Song, "Research progresses in the chemistry and pharmacology of Angelica sinensis (Oliv.) Diel," China Journal of Chinesemateriamedica, vol. 26, no. 3, pp. 147-155, 2001.

[5] W.-W. Chao and B.-F. Lin, "Bioactivities of major constituents isolated from Angelica sinensis (Danggui)," Chinese Medicine, vol. 6, no. 1, p. 29, 2011.

[6] D. Chen, J. Tang, N. H. Khatibi et al., "Treatment with Z-ligustilide, a component of Angelica sinensis, reduces brain 
injury after a subarachnoid hemorrhage in rats," Journal of Pharmacology and Experimental Therapeutics, vol. 337, no. 3, pp. 663-672, 2011.

[7] S. Wu, N. Wang, J. Li et al., "Ligustilide ameliorates the permeability of the blood-brain barrier model in vitro during oxygen-glucose deprivation injury through HIF/VEGF pathway," Journal of Cardiovascular Pharmacology, vol. 73, no. 5, pp. 316-325, 2019.

[8] L.-W. Qi, J. Cao, P. Li, and Y.-X. Wang, "Rapid and sensitive quantitation of major constituents in Danggui Buxue Tang by ultra-fast HPLC-TOF/MS," Journal of Pharmaceutical and Biomedical Analysis, vol. 49, no. 2, pp. 502-507, 2009.

[9] H. Bao, J. Chi, H. Yang, F. Liu, K. Fang, and Y. Xu, "Simultaneous determination of six active components in danggui kushen Pills via quantitative analysis of multicomponents by single marker," Journal of Analytical Methods in Chemistry, vol. 2019, Article ID 962057, 11 pages, 2019.

[10] Y.-L. Wang, Y.-Z. Liang, B.-M. Chen, Y.-K. He, B.-Y. Li, and Q.-N. Hu, "LC-DAD-APCI-MS-based screening and analysis of the absorption and metabolite components in plasma from a rabbit administered an oral solution of Danggui," Analytical and Bioanalytical Chemistry, vol. 383, no. 2, pp. 247-254, 2005.

[11] Y. Q. Xiao, L. Li, X. L. You, M. Taniguchi, and K. Baba, "Studies on chemical constituents of the rhizomae of Ligusticumchuanxiong," China Journal of Chinese Materiamedica, vol. 27, no. 7, pp. 519-522, 2002.

[12] K. J. Zhao, T. T. X. Dong, P. F. Tu, Z. H. Song, C. K. Lo, and K. W. K. Tsim, "Molecular genetic and chemical assessment of RadixAngelica(danggui) in China," Journal of Agricultural and Food Chemistry, vol. 51, no. 9, pp. 2576-2583, 2003.

[13] Z. B. Dong, S. P. Li, M. Hong, and Q. Zhu, "Hypothesis of potential active components in Angelica sinensis by using biomembrane extraction and high performance liquid chromatography," Journal of Pharmaceutical and Biomedical Analysis, vol. 38, no. 4, pp. 664-669, 2005.

[14] S. Li, Q. Han, C. Qiao, J. Song, C. L. Cheng, and H. Xu, "Chemical markers for the quality control of herbal medicines: an overview," Chinese Medicine, vol. 3, no. 1, p. 7, 2008.

[15] Z. Zhou, N. Li, H.-F. Zhang et al., "Simultaneous quantitative analysis of 11 flavonoid derivatives with a single marker in persimmon leaf extraction and evaluation of their myocardium protection activity," Journal of Natural Medicines, vol. 73, no. 2, pp. 404-418, 2019.

[16] Y. Qian, Y. Wang, R. Sa et al., "Metabolic fingerprinting of Angelica sinensis during growth using UPLC-TOFMS and chemometrics data analysis," Chemistry Central Journal, vol. 7, no. 1, p. 42, 2013.

[17] J. Liu, J. E. Burdette, H. Xu et al., "Evaluation of estrogenic activity of plant extracts for the potential treatment of menopausal symptoms," Journal of Agricultural and Food Chemistry, vol. 49, no. 5, pp. 2472-2479, 2001.

[18] L.-l. Wang, Y.-b. Zhang, X.-y. Chen, and S.-q. Chen, "Simultaneous quantitative analysis of main components in linderae reflexae radix with one single marker," Journal of Liquid Chromatography \& Related Technologies, vol. 39, no. 8, pp. 422-427, 2016.

[19] M. Liu, W. Xu, Q. Sun, H. Yang, and E. Liu, "Simultaneous determination of three constituents in Campanumoealancifolia by QAMS," Chinese Traditional Patent Medicine, vol. 41, no. 07, pp. 1612-1617, 2019.

[20] Y. Liu, W. Cai, Z. Dou, R. Cao, L. Ni, and L. Zhang, "Simultaneous determination of 12 lignans in Schisandrae Chinensis fructus by quantitative analysis of multi- components with single marker," Journal of Pharmaceutical Analysis, vol. 39, no. 7, pp. 1207-1216, 2019.

[21] Z. Li, D. Jiang, L. Weng, Y. Su, and X. Hou, "Simultaneous determination of three iridoid glycosides in different parts of Gentianae by QAMS," Journal of Pharmaceutical Analysis, vol. 39, no. 6, pp. 1069-1076, 2019.

[22] Z. Yao, J. Yu, Z. Tang et al., "Multi-evaluating strategy for sijikangbingdu mixture: chemical profiling, fingerprint characterization, and quantitative analysis," Molecules, vol. 24, no. 19, pp. 3545-3564, 2019.

[23] L. Tian, H. Yan, X. Fu, J. Wang, H. Guo, and Y. Chen, "Simultaneous determination of multiple components in decoction pieces of Chuanxiong Rhizoma and Angelicae Sinensis radix by quantitative analysis of multi-components by single maker," Journal of Pharmaceutical Analysis, vol. 34, no. 5, pp. 848-854, 2014.

[24] Y. Yang, Y. Liu, Z. Huang, Y. Liu, and Y. Chen, "Determination of senkyunolide A and ligustilide in Chuanxiong Rhizoma and Angelicae Sinensis radix by QAMS," Chinese Journal of Experimental Traditional Medical Formulae, vol. 21, no. 3, pp. 58-62, 2015.

[25] H. Yi, J. Zhou, X. Shang et al., "Multi-component analysis of Ilex kudingcha C. J. Tseng by a single marker quantification method and chemometric discrimination of HPLC fingerprints," Molecules, vol. 23, no. 4, pp. 854-873, 2018.

[26] N. Wang, Z.-Y. Li, X.-L. Zheng, Q. Li, X. Yang, and H. Xu, "Quality assessment of kumu injection, a traditional Chinese medicine preparation, using HPLC combined with chemometric methods and qualitative and quantitative analysis of multiple alkaloids by single marker," Molecules, vol. 23, no. 4, pp. 856-870, 2018. 